\title{
LA GUERRA DE SUCESIÓN EN VALENCIA. RETROSPECTIVA HISTORIOGRÁFICA Y ESTADO DE LA CUESTIÓN
}

\author{
CARMEN PÉREZ APARICIO
}

Universitat de Valencia

Cumplidos trescientos años desde que, en 1705, se iniciaran las sublevaciones de los Reinos de la Corona de Aragón a favor del archiduque Carlos y otros tantos desde que se abriera, en 1707, el proceso que acabaría con el sistema político que había regulado las relaciones entre el rey y la referida Corona, el conocimiento sobre este trascendental periodo histórico ha experimentado en los últimos cuarenta años un avance significativo.

Desde que en la década de 1960 se iniciara un proceso de reflexión y de análisis - sin parangón hasta entonces- sobre la trayectoria histórica del País Valenciano hasta la actualidad, el camino recorrido ha sido largo y fructífero y las favorables expectativas sobre su continuidad permiten albergar la esperanza de una andadura ininterrumpida, marcada por los sucesivos relevos generacionales y por la necesidad de ofrecer renovadas respuestas a nuevos interrogantes. En aquel momento, en el que otras generaciones desvinculadas del régimen político y de la ideología dominante reivindicaban más libertades, el ámbito de la Historia se había visto sacudido desde unos años antes por una corriente renovadora que recogida desde Francia por Jaime Vicens Vives, constituía un revulsivo para las esclerotizadas instancias académicas y amenazaba con echar por el suelo unos planteamientos historiográficos muy condicionados por un régimen político que había manipulado groseramente la Historia de España e impuesto una visión unitaria y al mismo tiempo parcial, tan alejada del rigor histórico como excluyente de las otras Historias de España. La Introducción a la Historia de España de A. Ubieto, J. Reglà y J. M. Jover, gestada durante la estancia de todos ellos en la

1. Ubieto, Antonio, Reglì, Juan, Jover, José María, Introducción a la Historia de España, Barcelona, 1962. 
Universidad de Valencia y a la que se incorporó después C. Seco, constituyó, desde su aparición en 1962, un auténtico revulsivo y un hito en el panorama historiográfico.

A principios de los años sesenta vio también la luz en Valencia la obra de Joan Fuster, Nosaltres, els valencians ${ }^{2}$ y cuyo autor, ajeno entonces al ámbito académico, ofreció una visión lúcida, crítica y provocadora que brindaba a la sociedad en general y al mundo intelectual en particular la oportunidad de reflexionar sobre el pasado, presente y futuro de los valencianos. En una etapa, pues, marcada por una mayor apertura ideológica y sobre todo por un renovado deseo de cambio social, los historiadores supieron recoger el reto lanzado por una sociedad que se mostraba cada vez más interesada por conocer su pasado, comprender su presente y asumir el reto de poder decidir su futuro. Artífices de este cambio trascendental en el ámbito de la historiografía valenciana fueron un grupo de historiadores, Reglà, Tarradell, Ubieto o Giralt, procedentes de los distintos territorios de la antigua Corona de Aragón, que recalaron por entonces en la Universidad de Valencia.

De todos ellos, Joan Reglà continúa siendo el principal referente para muchos de los historiadores valencianos actuales y no sólo del ámbito de la Historia Moderna. Ampurdanés de nacimiento y discípulo de Jaime Vicens Vives, supo impulsar una profunda renovación de los estudios históricos y convertirse, al mismo tiempo, en aquellos años ciertamente cruciales, en un modelo de humanidad, de tolerancia y, lo que era más importante, en un dignísimo y verdadero ejemplo de lo que él entendía como el necesario compromiso social del historiador. En este sentido, su obra Aproximació a la Història del Pais Valenciă ${ }^{3}$, publicada en 1968, constituyó un aldabonazo dentro y fuera de los muros del viejo edificio de la Universidad y se convirtió no sólo en el punto de partida de un nuevo y mayor interés por la historia valenciana, hecho desde planteamientos renovadores, sino también en el libro de cabecera con el que, además, algunos aprendices de historiador de entonces, poco familiarizados con una cultura que no era la nuestra, aprendimos a leer en la lengua de Ausias March, y a conocer y comprender una historia y una realidad, la del País Valenciano, que no por próxima nos era menos desconocida.

Fue en este contexto, en los seminarios que el prof. Reglà celebraba los jueves en su propio despacho donde un grupo de jóvenes estudiantes, bajo su dirección pero con el impulso también de uno de sus discípulos, el igualmente malogrado y llorado Sebastián García Martínez, empezó a dar sus primeros pasos en campo de la investigación histórica. Se abrieron camino de nuevo los grandes, y al mismo tiempo clásicos, temas de la historia valenciana, Fernando el Católico, las Germanías, la expulsión de los moriscos, el reinado de Carlos II, la Guerra de Sucesión, las Cortes valencianas, sin descuidar otros de temática más novedosa relacionados con los problemas económicos. Pues bien, el panorama historiográfico que ofrecía entonces la Guerra de Sucesión era ciertamente pobre. De entrada, la única obra específica sobre la rebelión de los valen-

2. FUSTER, Joan, Nosaltres els valencians, Valencia, 1962.

3. REGLÀ, Joan, Aproximació a la Història del País Valencià, Valencia, 1968. 
cianos, escrita en latín con el título De bello rustico valentino, era la que había salido de la pluma de un testigo de los acontecimientos, el religioso trinitario P. José Manuel Minyana, y había sido publicada en $1752^{4}$.

Cualquier historiador o curioso e interesado lector que entonces, como hoy, se acerque a la traducción al español de la obra de Minyana, es muy probable que experimente una primera sensación de desencanto. Todos los factores que pudieran ayudarnos a comprender las causas del conflicto internacional, el origen de la rebelión de los valencianos, los problemas surgidos durante el primer reinado del Borbón y bajo el gobierno del archiduque, y el verdadero alcance de la Nueva Planta quedan relegados a un segundo y a veces remoto o inexistente plano en favor del protagonismo que acapara el conflicto militar, lo que da pie a una mera narración de los hechos de armas llevados a cabo por los ejércitos borbónicos y las tropas aliadas en suelo valenciano durante el periodo que transcurre entre el inicio de la rebelión, en agosto de 1705, y el fin de las hostilidades, a principios de 1709, tras el triunfo borbónico.

Es más que probable que el hipotético lector asumiera como propias las consideraciones que en su día le hizo llegar el deán Martí, bajo cuya tutela se inició Minyana en el estudio de las lenguas clásicas y de la crítica literaria e histórica y con quien compartió las actividades literarias y científicas desarrolladas entonces por un grupo de novatores valencianos en la Academia del marqués de Villatorcas. La obra aparece dividida en tres libros, el primero de los cuales, que abarca desde 1705 hasta los primeros meses de 1706, estaba ya listo en julio de 1707, cuando el autor solicitó del deán sus comentarios. El segundo, que acaba en la batalla de Almansa, fue remitido por Minyana poco después. Ante la insistencia del discípulo, el maestro se vio forzado a redactar unas notas tanto sobre cuestiones literarias como históricas, pero que en este último aspecto no resultaban muy favorables. Opinaba el deán que la obra del trinitario era una mera narración de los acontecimientos militares que se habían desarrollado en el País Valenciano durante el periodo citado, mientras que el historiador, más que ofrecer una sucesión de hechos, debía precisar el contexto, analizar las causas y, en definitiva, buscar las razones que explicaran el porqué de aquello que narraba. Que además los acontecimientos recogidos tuvieran un carácter eminentemente bélico era motivo añadido de crítica y razón por la que el deán proponía dejar a un lado estos aspectos para introducir digresiones sobre las cuestiones políticas. No eran éstas, sin embargo, las únicas deficiencias de la obra, lastrada además por la falta total de referentes cronológicos en los hechos relacionados e incluso por algunas inexactitudes a la hora de recoger acontecimientos no vividos por el autor. Martí añadía también algunos reproches por algo que él consideraba impropio de un buen patricio, como era el no haber incluido en su relato los nombres de todos aquéllos que se habían mantenido

4. MNIANAE, Joseph Emmanuel, De bello rustico valentino, prólogo de Gregorio Maians, La Haya, 1752. La primera traducción al castellano fue publicada por Vicente Castañeda en Revue Hispanique, LV, New York, Paris, 1922, p. 447-618. Existe una nueva edición revisada del texto latino y nueva traducción: MiÑANA, José Manuel, La Guerra de Sucesión en Valencia, edición a cargo de F. Jordi Pérez i Durà y José Mả Estellés i González, Valencia, 1985 . 
fieles al Borbón y lo habían sacrificado todo para evitar las desventuras de su Patria porque, de esta manera, lo único que se proyectaba a través de la obra era la imagen de que todos los valencianos habían tomado parte en la violenta sublevación protagonizada por los campesinos. Lo que Martí parece querer decir entre líneas es que, al cargar tanto las tintas contra los partidarios del archiduque y centrar su relato en las actuaciones de éstos, Minyana acentuaba el pecado de la rebelión y daba pié -aunque inconscientemente- a la imposición de una dura y duradera penitencia. No hay que olvidar que Martí redactaba sus «monita» en unas circunstancias, en las que un sector importante de la clase política valenciana seguidora de Felipe V, había manifestado su profundo malestar por el decreto de abolición de los Fueros, al considerarlo un castigo desproporcionado e indiscriminado.

Las críticas a la forma y al fondo de la obra de Minyana hicieron profunda mella en el trinitario, quien por otro lado atravesaba en aquellos momentos por una fase de profundo desánimo personal, reflejo a su vez de la tristeza colectiva que afectaba a la sociedad valenciana en esta etapa de represión y de aplicación de las primeras medidas de la Nueva Planta de gobierno. En respuesta a las mismas, escribió una carta de 5 de diciembre de 1707 en la que, en general, se mostraba reacio a admitir las críticas y sugerencias hechas por su maestro. Para empezar, no consideraba necesario dar principio a su obra con una exposición más amplia sobre las causas de la guerra y las intenciones de los príncipes contendientes. «Que haga esto el que haya suscitado todo el asunto», afirmaba, pero, al tiempo que se ratificaba en su propósito inicial de tocar sólo tangencialmente estos temas, se mostraba al final condescendiente y dispuesto a recoger en parte esta observación. También se ponía a la defensiva sobre la cuestionada credibilidad de las fuentes utilizadas, refutando algunas de las objeciones formuladas por Martí, si bien reconocía la necesidad de disponer de más información sobre algunos episodios de los que no había sido testigo. Más receptivo se mostraba en cuanto a incluir referencias más precisas sobre las fechas y una mejor descripción de los lugares, pero en general trataba de justificarse ante las objeciones de fondo que le había hecho llegar su maestro. Así, se escudaba en Salustio y Livio, quienes «en la descripción de los crímenes del pueblo romano, hablaron con bastante libertad), para mantener el tono de sus acusaciones contra las clases populares y en cuanto a la relación de los fieles del Borbón, consideraba ésta una tarea no sólo pesada, sino odiosa, «porque yo me he encargado de una Historia del pueblo, no de escribir los elogios de cada uno de ellosin.

En definitiva, Minyana acusaba el golpe de tan acerada y profunda crítica y, en su respuesta, si bien agradecía los favores del maestro, reflejaba también un distanciamiento bastante firme respecto de las objeciones, más bien «reprimendas»), que se le formulaban y que consideraba y tachaba de desmesuradas. El propio Martí calificaría, años más tarde, de «carta desacordada» la respuesta enviada por su discípulo y atribuía a este hecho la causa del distanciamiento entre ámbos. Todas estos pormenores

5. Ibidem, págs. 300-304, carta de Minyana a Martí. 
explicarían que el Libro Tercero de la obra no fuera revisado por Martí, sino remitido a Maians en una fecha bastante tardía como la de 1723. A propósito del retraso en la redacción de la última parte, nada se sabe con certeza. El propio autor, en la carta respuesta a Martí de 5 de diciembre de 1707 ya mencionada, aseguraba encontrarse en un estado de ánimo poco propicio para la pluma. Por estas fechas había renunciado a la cátedra de Retórica que ocupaba en la Universidad y se había recluido en el convento aquejado de un profundo desánimo, causado, según él mismo confiesa, por las difíciles y dolorosas circunstancias que afectaban a la sociedad valenciana.

El papel desempeñado por Maians acerca de la última parte del texto fue muy diferente del que había realizado Martí con los dos primeros libros. El propio erudito de Oliva se lamentaba, pasado el tiempo, de que el deán no lo hubiera visto y se excusaba en el hecho de que por aquellas fechas él mismo se hallaba inmerso en la preparación de la cátedra de Justiniano para explicar que tan sólo hiciera algunas objeciones al estilo. Con todo, Maians formularía años después, a propósito de la publicación, su juicio sobre la obra. Entre los aspectos cuestionables, se limitaba a recoger la crítica, ya formulada por Martí, acerca de la falta de suficientes referencias cronológicas, si bien añadía por su cuenta que hubiera deseado un mayor cuidado y atención a los temas relacionados con la Historia del Derecho, máxime después del cambio radical que se había introducido con la Nueva Planta. Por otro lado, ensalzaba Maians algunos de los valores del Tercer Libro y en especial la mayor elocuencia respecto de los dos libros anteriores. Sobre la obra, en general, destacaba la veracidad a la hora de narrar los hechos, virtud que diferenciaba a su autor de todos aquellos que habían empleado su pluma con el mismo fin. También consideraba digno de elogio el estilo narrativo del texto, muy por encima, a los ojos del erudito, de la Continuación de la Historia de Mariana que había escrito poco después. En su opinión se trataba, además, de una «historia amenisima» y, lo que consideraba más importante, «escrita con prudencia y libertad, si bien hay que confesar publicamente que fue muy afecto a Felipe V Rey de España $\rangle^{6}$. En definitiva, Maians se mostraba mucho más favorable en sus opiniones que el deán Martí, pero no hay que olvidar que fueron escritas para acompañar la edición de De bello rustico valentino, aparecida en La Haya en 1752.

Desde la perspectiva actual, y a pesar de los comentarios críticos vertidos por sus coetáneos, la obra de Minyana es de un valor incuestionable, sobre todo teniendo en cuenta que es el único testimonio en el desierto historiográfico que es el Setecientos

6. Prólogo de Gregorio Maians a la obra de Minyana. Seguimos en este caso la traducción de Castañeda, $o p$. cit., págs. 452-453. Resulta más coherente desde el punto de vista histórico que la efectuada por Pérez i Durá y Estellés i González, quienes traducen: «Historia agradabilísima (...) escrita con prudencia y liberlad; y para decirlo claramente, que éste fue el más apreciado por Felipe V, Rey de las Españas》, op. cit., pág. 309. De este último tex to no se deduce claramente si el más apreciado por Felipe $V$ fue su autor, cuestión ésta discutible si se le compara con la figura y la obra de Belando que más adelante analizaremos, o si la más valorada fue su obra, que tampoco admite comparación con la de Belando, puesto que esta última abarca un periodo y un ámbito muy superiores. Además, teniendo en cuenta que el trabajo del valenciano se publicó después de morir el primer Borbón, queda la duda de si el rey conoció el manuscrito y, caso de ser así, de por qué no impulsó su publicación, como sí que ocurrió con la obra de Belando. 
valenciano. Dejando a un lado los valores literarios que pueda tener, hay que reconocer en ella el propósito de su autor de respetar la verdad y de recoger sólo aquellos hechos vividos personalmente o de los que contara con testimonios fidedignos. Sin embargo, el rigor con el que se narran los acontecimientos se ve en general limitado por la falta de precisiones cronológicas, que sólo esporádicamente aparecen en el texto, y al mismo tiempo empañado por las descalificaciones que dispensa a los seguidores del Archiduque en general y a los sectores populares en particular.

La obra sitúa sus comienzos en 1705 , año en el que estalló la revuelta valenciana a favor del archiduque Carlos, con una brevísima digresión sobre la actitud europea y sobre los intereses de los dos bloques en conflicto, para analizar seguidamente las causas que habían dado lugar al descontento de castellanos, catalanes, aragoneses y valencianos hacia la Casa de Borbón. Según él, quedaban limitadas a dos, la fidelidad a la Casa de Austria y la antigua enemistad con Francia, agravada por el comportamiento abusivo de los comerciantes franceses. Antes de iniciar su relato, perfila los grandes rasgos de la estrategia aliada, el porqué de su presencia en el Mediterráneo y el desembarco en Altea en 1705. Tras ello, presenta a Basset como un personaje de origen modesto y antecedentes oscuros, artífice de la sublevación y líder popular, cuya actuación en estos primeros momentos no fue otra sino la de incitar a los campesinos a la revuelta con promesas de mejora de las condiciones señoriales. Formula, pues, Minyana la idea del protagonismo popular en los acontecimientos y, al mismo tiempo, el carácter reivindicativo de los mismos, aunque abandona rápidamente este buceo en las raíces profundas de las motivaciones populares para pasar en derechura a la narración de los hechos. A partir de aquí entra de lleno a relatar los diferentes movimientos de tropas que se suceden en el País Valenciano con el fin de frenar las sublevaciones de Dénia y de Vinaròs y cuyo fracaso evidenció claramente la inoperancia del gobierno borbónico. La capitulación de la ciudad de Valencia y la proclamación del archiduque Carlos se presenta como el fruto de la traición cometida por algunos personajes destacados de la sociedad valenciana, el conde de Cardona, don Manuel Mercader y José Vicente Torres y Eiximeno y, al mismo tiempo, como el resultado de un claro apoyo popular protagonizado por los gremios de la capital. Es en este punto cuando Minyana, siguiendo alguna de las críticas formuladas por Martí, se decide a introducir en la narración los nombres de todos aquéllos que rehusaron adherirse al nuevo gobierno.

Aunque la rendición de Valencia abría las puertas a una nueva etapa de gobierno, la pluma de Minyana no fue muy prolija a la hora de analizarla. Se limita a hacer unos breves, pero durísimos, comentarios sobre el nuevo dirigente, Basset, a quien acusa cometer todo tipo de tropelías contra los partidarios del Borbón, todas ellas respaldadas por los sectores sociales más desfavorecidos que, desde el primer momento, se habían unido a él. Tampoco se libraron de descalificaciones contundentes otros destacados austracistas como el virrey, conde de Cardona, de cuya acción de gobierno apenas si destaca la persecución infringida a los fieles partidarios del Borbón.

E1 Libro Primero y el Segundo se unen sin solución de continuidad en la narración a veces farragosa- de los hechos de armas que se desarrollan a lo largo y ancho del País Valenciano durante la primavera y verano de 1706 y que fueron protagonizados 
por los ejércitos de ambos contendientes. Las múltiples escaramuzas, que se suceden aquí y allá, pero, sobre todo, el asedio aliado de Alacant, centran la atención del historiador, quien -también hay que señalarlo- no dudó en condenar la muerte de muchos inocentes a manos del ejército filipista tras su entrada en Elx. Este hilo narrativo se interrumpe para dar paso a la llegada del archiduque a la capital del Reino. Es en este punto cuando aflora de nuevo el análisis histórico para dar cuenta brevemente de algunas de las medidas de gobierno adoptadas por el nuevo rey, en especial de aquéllas que afectaban a los intereses económicos del clero. Sin embargo, las actuaciones de los respectivos ejércitos recuperan de nuevo el protagonismo de la narración e imponen su presencia hasta desembocar en el gran plano de la batalla de Almansa.

El Libro Tercero y último se inicia el día después de la batalla siguiendo el camino recorrido por el ejército victorioso tras su llegada a tierras valencianas. Dedica gran atención a la entrada de las tropas en la capital y de nuevo carga las tintas contra el populacho por su resistencia a capitular, si bien destaca y ensalza la actitud prudente y moderada prestada por determinados personajes y colectivos en estos difíciles momentos. A Valencia siguieron otras poblaciones, Alzira y especialmente Xàtiva, donde el historiador da verdaderas pruebas del esfuerzo por mantener el rigor de su narración y el respeto a la verdad, incluso en situaciones tan comprometidas para la causa borbónica como las derivadas de la destrucción de esta última ciudad, puesto que, a diferencia de otros historiadores coetáneos, no dudó en atribuir la paternidad de tan cruel e innecesaria medida al propio ejército borbónico en la persona de su comandante, D'Asfeld, si bien es verdad que, tras esta atribución, hay un claro intento de ocultar que la orden de destrucción vino de Madrid bastante tiempo después de recuperada la ciudad y que el propio Felipe $V$ no fue ajeno a la misma.

El último libro mantiene la tónica narrativa de los anteriores, centrada ahora en el proceso de recuperación de todas las poblaciones valencianas que habían perseverado en su actitud rebelde hacia el ejército borbónico. Una por una, hasta llegar a la rendición de Alacant, Minyana va desgranando, sin referencias cronológicas pero tratando de respetar la secuencia de los acontecimientos, todas las actuaciones militares. Sin embargo, en esta parte tiene que hacerse eco también de los problemas políticos y sociales derivados de la guerra. En primer lugar de la abolición de los Fueros, respecto de la cual contrapone la antigua «libertad» a la presente «servidumbre», aunque en ningún momento hace suyas las quejas por el carácter indiscriminado del castigo y sí se hace eco de las razones esgrimidas por los vencedores para justificarlo. Al mismo tiempo, como observador y testimonio de la nueva situación, no duda en recoger el amplio malestar social provocado por la aplicación de las nuevas leyes y denunciar la política de represión aplicada sobre los vencidos. Al respecto, hay que decir que no escatima críticas al comportamiento del ejército vencedor por su actitud de altanería y orgullo y por la soberbia y avaricia con la que los jefes militares trataban a los infelices pueblos ${ }^{7}$.

7. MÑANA, De bello rustico ..., op. cil., págs. 574-575 y La Guerra ..., op. cit., págs. 225-228, respectivamente. 
También se hace eco del fenómeno de los migueletes, pero en ningún momento da a éstos su verdadera dimensión social y política, es decir, la de constituir un movimiento de resistencia al gobierno borbónico que, a modo de guerrilla, trata de frenar el avance de las tropas, sino que, por el contrario, y siguiendo con las propias órdenes dictadas por el gobierno borbónico, alude siempre a ellos con el apelativo de «ladrones», a fin de erradicar las connotaciones patrióticas de estos grupos.

En definitiva, la obra de Minyana, con sus limitaciones y sus aciertos, sigue constituyendo, hoy en día, una fuente básica para el conocimiento de los años cruciales que transcurren entre 1705 y 1709. A diferencia de otras obras históricas sobre el reinado de Felipe V, como la del marqués de San Felipe o la de Belando, que vieron la luz en los años posteriores al conflicto, la obra de Minyana permaneció inédita hasta 1752 , a pesar de que las dos primeras partes estaban ya redactadas en $1707 \mathrm{y}$ la tercera y última en una fecha no precisada pero anterior a 1723. Llama, pues, la atención, el largo periodo transcurrido hasta su publicación en 1752, que no puede justificarse solamente en el hecho de que el manuscrito estuviera un tiempo en paradero desconocido, como explica Maians ${ }^{8}$. Pero no es menos destacable el hecho de que no viera la luz en imprentas valencianas o españolas, sino en las de la lejana Holanda, y no a impulso de quienes de una $\mathrm{u}$ otra manera se habían visto afectados por los avatares bélicos o sus consecuencias, sino gracias al interés y a la iniciativa del erudito conde de Linden, quien solicitó de su corresponsal Maians el envío de libros y manuscritos de antigüedades, historia o jurisprudencia dignos de ser reimpresos o de publicarse por vez primera ${ }^{9}$. Es cierto, sin embargo, que el erudito de Oliva llevó a cabo años antes algunas diligencias al respecto. De hecho, en 1734, el canónigo don José de Castellví le remitió la obra de Minyana para su revisión y dos años más tarde su hermano, el conde de Cervelló, desde su exilio en Viena, manifestaba su interés por recibirla y publicarla ${ }^{10}$. No fue posible. El resultado traumático que para los valencianos - de cualquier filiación política - tuvo el conflicto sucesorio, puede explicar las dificultades encontradas, incluso entre los propios intelectuales austracistas, para editar la referida obra ${ }^{11}$. Llama la atención incluso que el propio Maians, distanciado ya también de la causa austracista abrazada por su padre, reproche a los seguidores del archiduque el haber dado motivo a la abolición de los Fueros, aunque por otro lado mantenga el tono quejumbroso hacia esta decisión de Felipe $\mathrm{V}$ y considere el tema «molesto» para los valencianos. De todas formas, el hecho de que la obra estuviera escrita en latín y se publicara en Holanda,

8. Según explica Maians, él mismo hizo diversas diligencias para publicar la obra con la Contintración de la Historia del P. Mariana. Prólogo de Antonio Mestre a MIÑANA, La Guerra..., op. cit., XIIl-XIV.

9. PESET, Vicent, Gregori Maians i la cultura de la Il-lustració, Barcelona, 1975, pág. 111.

10. MAYANS Y CISCAR, Gregorio, Epistolario XXI. Mayans y los austracistas, estudio preliminar, transcripción y notas de Antonio Mestre Sanchis, Valencia, 2006, págs. 180-182, 203, 262, 477, 479, 485 y 486.

11. El mismo Maians confiesa a Linden que la obra de Minyana es «por su tema muy molesta para los valencianos unicamente, pues perdimos a causa de la locura de unos pocos hombres, en un solo instante de una época desgraciadisima, los derechos adquiridos a través de tantos siglos». Carta de Maians al conde de Linden de 7 de septiembre de 1752. Reproducida en MiÑANA, La Guerra..., op.cit., pág. 306. 
limitó necesariamente su proyección al campo erudito, sin que los votos formulados por el ilustrado valenciano para una pronta traducción se vieran cumplidos hasta casi dos siglos después.

Muy similares fueron las vicisitudes que rodearon la publicación de las memorias del conde de Robres, que permanecieron inéditas hasta 1882. Su autor, de clara filiación borbónica, como Minyana, fue también un testigo excepcional de los acontecimientos, vividos en la primera fila de la escena política. Su obra rezuma un amplio bagaje intelectual y una sólida formación histórica y política y se caracteriza y destaca por una escrupulosa imparcialidad y por una capacidad de análisis y de juicio claramente excepcionales en el panorama historiográfico sobre la Guerra de Sucesión. De otro lado, su origen aragonés y catalán y su conocimiento del sistema político y del entramado institucional de la Corona de Aragón, convierten sus Memorias en lectura inexcusable para comprender el conflicto sucesorio desde una perspectiva periférica. Por lo que se refiere al asedio de Xàtiva por las tropas borbónicas, no dudó en hacerse eco de las atrocidades cometidas por el ejército contra los defensores de la población. Todos los defensores fueron exterminados por resistirse a las tropas de D'Asfeld, pero, en su opinión, la actitud temeraria de los setabenses no justificaba el furor y la venganza con la que se comportaron los vencedores contra la población civil, deportada a Castilla, confiscados sus bienes y destruida finalmente la ciudad por una orden aprobada en la Corte ${ }^{12}$.

Mejor suerte corrieron las obras del marqués de San Felipe y de Belando, que fueron publicadas en vida de Felipe V, pero el hecho de tratarse, como la de Robres, de obras generales sobre la guerra y el reinado del primer Borbón explica que su interés sea limitado desde la perspectiva estrictamente valenciana. La obra del marqués de San Felipe $^{13}$, aparecida en 1725 , es, sin duda, la más ambiciosa de las que se publicaron durante la centuria. Militar y diplomático sardo al servicio del Borbón, con quien mantuvo una cierta amistad, también literato, fue testigo y protagonista de unos acontecimientos que recoge en general con rigor e imparcialidad, virtudes ámbas que no pudieron evitar que el Borbón, disconforme con el tratamiento dado en distintos pasajes de la obra a la actitud de diferentes personajes, ordenara su retirada en el mismo año de su publicación ${ }^{14}$. San Felipe muestra, además, una gran capacidad narrativa y analítica, lo que le sitúa en conjunto a mucha distancia de Minyana. Sin embargo, como es lógico, las referencias al País Valenciano son muy escasas y a veces confusas, si bien predomina la exactitud y la concisión. Desde una postura comprometida con el Borbón, utiliza un lenguaje moderado para referirse a los partidarios del archiduque, aunque no ahorra duras críticas a las clases populares ni mucho menos a su líder, el general Basset. No

12. LOPEz de MENDOza y PONS, Agustín, Historia de las Guerras civiles de España, Zaragoza, 1882, págs. 343-344.

13. BaCAllar y SANna, Vicente, marqués de San Felipe, Comentarios de la Guerra de España e historia de su rey Felipe V el Animoso, Génova, 1725?, nueva edición y estudio preliminar de Carlos Seco Serrano, Madrid, 1957.

14. Ihidem, Prólogo de Carlos Seco, LXXI. 
obstante, la obra revela cierta falta de rigor en algunos pasajes, lo cual es comprensible en una obra de tan gran envergadura, y en otros muy puntuales una clara y grosera manipulación de los hechos, como, por ejemplo, cuando pretende atribuir el incendio de la ciudad de Xàtiva, llevado a cabo en junio de 1707, a la acción desesperada de los austracistas sitiados por las tropas del francés D'Asfeld ${ }^{15}$. De esta forma tan burda trata de ocultar que la total destrucción de la ciudad se produjo, de manera premeditada, casi un mes después de ocupada la ciudad por el ejército borbónico, en cumplimiento de las órdenes dictadas por el propio rey, que se mostró insensible a las peticiones de clemencia formuladas. A favor del historiador hay que apuntar la valentía con la que reflejó algunos episodios dramáticos que ponían en entredicho la política llevada a cabo por el gobierno borbónico ${ }^{16}$.

La obra del alicantino fray Nicolás de Jesús Belando completa el panorama historiográfico del XVIII español ${ }^{17}$. Bajo un enfoque también borbónico, el autor manifiesta en el prólogo su propósito de escribir «desnudo de pasión», lo que se deja notar en el tono ponderado de la narración y de los juicios, tan alejados, por ejemplo, de los excesos verbales descalificatorios del también eclesiástico Minyana. Este afán por conseguir un tono moderado y pretendidamente aséptico y sobre todo su intención de respetar al máximo el deseo de Felipe $\mathrm{V}$, que «no quiere que se diga cosa alguna contra particulares ni contra la Monarquía», le obligó a ocultar aquellos aspectos que podían resultar más problemáticos, como él mismo lo anuncia: «aunque no lo digo todo no falto a la verdad de la narrativa》. A pesar de ello, no escatima descalificativos contra los campesinos valencianos seguidores del archiduque Carlos, a los que tacha de «facinerosos y forajidos», y en cuanto a la veracidad de su relato es algo dudosa cuando se hurga en algunos de los episodios más dramáticos de la guerra. La noticia de la destrucción de Xàtiva, por ejemplo, no permite a Belando superar la prueba de esa pretendida objetividad. Como también hiciera el marqués de San Felipe, exonera al Borbón de su exclusiva responsabilidad en la orden de incendiar y arrasar la ciudad, cuya población se aproximaba a los diez mil habitantes. Para ello no duda en exponer la tesis de la autoría compartida entre borbónicos y austracistas ${ }^{18}$. En su afán por exculpar al rey de las decisiones más criticadas, tampoco se priva Belando de formular opiniones más que discutibles. Así, respecto del tan denostado por todos los valencianos Decreto de 29 de junio de 1707, dice que los Fueros «más fueron moderados que abolidos, pues no en todo espiraron sino que en parte se suspendieron» ${ }^{19}$.

15. Ibídem, pág. 132.

16. Idem.

17. Balando, Nicolás de Jesús, Historia Civil de España. Sucesos de la Guerra y Tratados de Paz desde el año de Mil Setecientos hasta el de Mil Setecientos Treinta y Tres, 2 vols., Madrid, 1740.

18. Ibidem, I, págs. 313-314.

19. Es cierto que el rey se vio obligado a restaurar algunos Fueros, sobre todo aquéllos que eran más favorables a la potestad real o al Real Patrimonio, pero fueron escasos. Por el contrario, la abolición afectó de pleno al sistema pactista e incluso al derecho civil, que no fue restaurado a pesar de las peticiones formuladas por las instituciones valencianas. 
Así pues y aunque resulte llamativo, De bello rustico valentino es, con todas sus limitaciones y aciertos, la primera y única historia de la Guerra de Sucesión en el País Valenciano hasta los tiempos actuales y punto de arranque de toda la literatura posterior. En el siglo XIX, otros historiadores se han ocupado del tema, pero, o bien han derivado hacia la defensa de los Fueros, o han tratado el periodo en el contexto de historias más generales. El primero es el caso de Borrull y Vilanova, cuya obra fue publicada en $1810^{20}$. El hecho de haber sido elaborada en unas circunstancias históricas excepcionales, explica que el enfoque y el alcance de la misma sean de carácter eminentemente político. Ya de entrada, establece como punto de partida un claro paralelismo entre la llegada de Felipe $V$ y de su ministro Amelot, a quien atribuye el plan para suprimir las leyes forales, con la invasión napoleónica. La obra rezuma francofobia por los cuatro costados, planteamiento éste muy alejado del de las obras escritas durante el reinado de Felipe $\mathrm{V}$.

En el caso de Borrull estamos ante un trabajo que no aporta nuevos elementos documentales, sino que tiene como objetivo demostrar la injusticia que supuso la abolición de los Fueros, cuya finalidad no era otra que la de acabar con la constitución y la libertad del Reino de Valencia. Este hecho marcaba para su autor el punto de partida para reivindicarlos, precisamente en unos momentos en los que el absolutismo borbónico llegaba a su fin y se abrían las puertas a la recuperación de las libertades políticas. Borrull se sumaba así a una corriente surgida desde el mismo momento de la publicación del decreto y de la que Minyana ya se había hecho eco. En la línea argumental expuesta ya en 1707 por la Ciudad de Valencia para manifestar la disconformidad de los valencianos con el decreto abolicionista, y utilizando profusamente la obra de Minyana, trataba de fundamentar la nulidad del decreto sobre la inexistencia del delito de rebeldía y la falta de potestad real para decretar la abolición. Aportaba nuevas razones para demostrar que sólo uno de los tres Estamentos valencianos -el Real-se rebeló contra el rey, mientras que los otros dos -Eclesiástico y Nobiliario- se mantuvieron fieles al Borbón, por lo que no se podía afirmar que el Reino hubiera sido rebelde ya que la mayor parte de su representación había permanecido fiel. Y puesto que no hubo unanimidad, cualquier disposición real que obligara a todos ellos sería, en consecuencia, contraria a la legislación foral, un argumento ratificado por el hecho de que el rey no tenía facultad para abolir, mudar o corregir los Fueros valencianos. Esta medida había sido también contraria a la razón natural y a las propias leyes de Castilla, según las cuales no pueden pagar unos por los delitos de otros. En definitiva, consideraba que el decreto había sido nulo y que, por lo tanto, los Fueros permanecían vigentes.

En la misma línea argumental, Borrull defiende que, por el contrario, fueron Felipe $V$ y el virrey quienes, con su inoperancia, facilitaron el desembarco enemigo y la capitulación de Valencia y señala que si hubo poblaciones que aclamaron a Carlos III, lo hicieron movidas por el temor a las represalias del ejército aliado. Manifiesta

20. Borrull y Vilanova, Francisco Xavier, Fidelidad de la Ciudad y Reyno de Valencia en tiempo de las Guerras Civiles que empezaron en el año 1705 , Valencia, 1810. 
un firme empeño en demostrar la incompetencia e incapacidad del ejército borbónico, que contrapone a la llegada de grandes contingentes de tropas aliadas. A pesar de todo, de las cuatro fortalezas valencianas, Alacant, Dénia, Montesa y Peníscola, sólo una, Dénia, se entregó a los aliados y muchas otras poblaciones, como Xixona, Elx, Sagunt o Morella, resistieron tenazmente. Su afán por demostrar la falta de rebelión y exculpar de ella a los valencianos, le lleva incluso a situarse en la comprometida tesitura de asegurar que Xàtiva no era austracista y que su encarnizada resistencia a las tropas borbónicas fue fruto de la presencia de una guarnición aliada. En este sentido, las noticias recogidas por el marqués de San Felipe sobre la total indefensión de las costas, la falta de previsión del gobierno borbónico y la inoperancia del virrey le permitían rebatir, con testimonios filipistas, lo injusto e injustificado de la abolición.

En clara sintonía con el alegato de Borrull en favor de lo que llama «libertad》, hay que situar la obra de Vicente Boix, Historia de la Ciudad y Reyno de Valencia, publicada en $1845^{21}$. En ella pretende seguir el camino trazado por los cronistas clásicos de la Edad Moderna, Viciana y Escolano, si bien en este caso se presta también atención a los acontecimientos de la guerra en el País Valenciano a partir de las obras ya publicadas de Minyana, el marqués de San Felipe y Belando, a las que incorpora algunas fuentes documentales de carácter complementario y tangencial. Sin menospreciar los hechos militares, se sitúa en un plano analítico para tratar de establecer las causas del conflicto. Su punto de vista recoge las tesis, ya mencionadas, de la indefensión de los valencianos por la falta de previsiones del propio gobierno borbónico y la inoperancia del virrey, al tiempo que resalta el carácter minoritario de los seguidores del Archiduque, a los que descalifica -como hizo Minyana en su momento- tachándoles de la «canalla más soez y despreciable», movidos por el espejismo de las promesas del general Basset. Añade la existencia de diversas razones para el descontento hacia Felipe V, resumidas en el rechazo de una dinastía extranjera y de un monarca que se rodea de una corte también extranjera. No se recata tampoco de criticar la ambición de los partidarios del archiduque y sus críticas salpican por igual a unos y otros. Sobre Basset no escatima descalificaciones por su responsabilidad en el clima de anarquía en el que se sumió la capital del Reino tras la proclamación de Carlos III. Del primer Borbón censura sus errores de gobierno, especialmente su menosprecio hacia la tradición política hispana -tan diferente de la francesa-, su afán de gobernar la Monarquía con un modelo importado y, por supuesto, la «injusta» abolición de los Fueros, que califica, además, de premeditada. Responsabiliza a los dos partidos del clima de violencia y extorsión que se vivió tras la batalla de Almansa, los dos son tachados de ciegos y fanáticos y de responsables de la ruina del País Valenciano, víctima de su encono. Culpa a las tropas aliadas extranjeras de la resistencia militar contra el ejército vencedor y afirma, como colofón, que Felipe $\mathrm{V}$ había sido, a pesar de todo, uno de los príncipes más dignos que había tenido España.

21. BolX, Vicente, Historia de la Ciudad y Reyno de Valencia, 3 vols., Valencia, 1845-1847. 
Diferentes planteamientos presenta la obra de Juan Bautista Perales ${ }^{22}$, que marca un punto de inflexión en el panorama historiográfico. Era el suyo un proyecto ambicioso como el de pretender continuar la obra de Escolano allí donde éste la había dejado, incorporando por primera vez de forma significativa la documentación de los archivos valencianos. Su propósito inicial queda claro: tras acusar de parcialidad a casi todos los historiadores que le habían precedido, especialmente al marqués de San Felipe y a Belando, a los que tacha de ser «aduladores del poder», se propone reivindicar la imagen y la historia de los vencidos, rebatiendo con hechos las censuras que se lanzaron sobre todos ellos. Especialmente crítico se muestra con el marqués de San Felipe, por Ilamar «insolentes» a los valencianos y no desaprovecha la ocasión para denunciar que Borrull o Boix no rechazaran tal descalificación. Sale al paso de las acusaciones que calificaban a los seguidores del Archiduque de gente soez y desmandada y, aunque no niega la violencia de sus actuaciones, la considera menor que la llevada a cabo por el ejército borbónico con el saqueo y destrucción de muchas poblaciones y entre ellas Xàtiva, hecho que atribuye directamente a Felipe $\mathrm{V}^{23}$.

De Basset ofrece una visión muy alejada de la conocida hasta entonces, la imagen de una persona cuyo origen no era tan humilde como se había venido reflejando hasta entonces y cuya sólida formación profesional le había llevado a alcanzar el grado de ingeniero. La obra de Perales refleja, pues, una actitud claramente crítica hacia todos los historiadores que le habían precedido y marca también un giro interpretativo respecto a todos ellos. Pero además, a diferencia de Borrull y Boix que habían sustentado sus tesis sobre las obras impresas del siglo XVIII, Perales es el primero en hacer uso de las fuentes archivísticas y eso le permite dar también un salto cualitativo en el estudio de la guerra al incorporar, de manera rigurosa, la secuencia cronológica de los acontecimientos. Ante el mismo hecho de la rebelión su postura es clara: exonerar a los valencianos y responsabilizar al gobierno de Felipe $\mathrm{V}$-en sintonía con los historiadores decimonónicos-, y por supuesto criticar la abolición de los Fueros calificándola de «monstruosa centralización creada por Luis XIV».

Aunque de distinta entidad que los recogidos hasta ahora, hay que hacer mención de los trabajos realizados por el canónigo Roque Chabàs sobre distintas cuestiones relacionadas con la Guerra de Sucesión en el País Valenciano. Tanto su Historia de Denia como los artículos publicados en la revista El Archivo constituyen aportaciones de cierto interés para el tema, especialmente por el hecho de utilizar fuentes manuscritas, en general inéditas, y por tratar de personajes importantes, como el propio Basset, $o$ de episodios decisivos en el desarrollo del conflicto como la sublevación de Dénia ${ }^{24}$.

22. PERAles, Juan Bautista, Décadas de la Historia de la Insigne y Coronada Ciudad y Reino de Valencia. Tercera Parte. Continuación de las Décadas que escribió el Licenciado y Rector Gaspar Escolano. Valencia, 1880.

23. Ibidem, pág. 841

24. GHABÁs, Roque, «Baset y las Guerras de Sucesión», El Archivo, I, n 14, Denia, 1886, págs. 105-107, n⿳15, págs. 113-115, n¹6, págs. 121-123 y n 17, págs. 129-131. Existe edición facsímil publicada en 
De otro lado, los deseos mayansianos de que la obra de Minyana fuera pronto traducida del latín no se vieron cumplidos, ni durante el siglo XVIII ni en la centuria posterior. Esta circunstancia, junto con el hecho de que la única edición existente hubiese aparecido en Holanda, debieron limitar considerablemente su difusión. De bello rustico valentino no fue trasladada a una lengua vulgar, en este caso el español, hasta 1922 y lo fue de la mano y pluma de Vicente Castañeda y Alcover, quién en el preámbulo pone de relieve que su objetivo no es otro que el de ofrecer a los valencianos la obra fundamental sobre «un tema que apasiona grandemente» y «de actualidad siempre entre los valencianos (...) que por desgracia fue el antecedente de la pérdida de las libertades valencianas que consagraron los Fueros». Aunque expuesta muy sucintamente, Castañeda añade su crítica a las ya formuladas por los historiadores valencianos hacia Felipe $\mathrm{V}$, a quien responsabilizaron de la sublevación por la falta de previsiones de guerra y de ayuda para la defensa del Reino y mantiene la corriente formulada por borbónicos y austracistas de reivindicar los Fueros, en su opinión «una de las legislaciones más democráticas y cultas, que cayó envuelta en el castigo impuesto por el agravio de los menos, en daño y desdoro de los más». La traducción del libro de Minyana no representaba una aportación historiográfica, pero se trataba sin duda de un paso significativo en la difusión de un tema de interés general. Hay que añadir, sin embargo, que tampoco en esta ocasión pudo realizarse en prensas valencianas o españolas, sino en las de la ciudad belga de Brujas, donde se imprimió el tomo LV de la Revue Hispanique, una revista editada por la Hispanic Society of America y dedicada, como reza en su cabecera, al estudio de las lenguas, de las literaturas y de la historia de los países castellanos, catalanes y portugueses. La limitada proyección de la citada revista constituyó, sin duda, un obstáculo más para la difusión de la obra de Minyana entre los valencianos, que no ha sido subsanada hasta tiempos bien recientes con la edición crítica del texto latino y una nueva traducción al español, realizada esta vez por F. Jordi Pérez Durà y José $\mathrm{M}^{a}$ Estellés Gonzále $z^{25}$. Se trata en este caso de una iniciativa necesaria y encomiable que brinda al estudioso y al gran público la oportunidad de conocer directamente una obra de acceso muy restringido hasta entonces, si bien los autores de la edición han dado primacía a los aspectos linguísticos y estilísticos de la obra original pero han obviado las limitaciones de carácter histórico, desaprovechando la oportunidad de compensar las deficiencias que fueron señaladas ya en su día por el deán Martí.

La problemática de la Guerra de Sucesión reapareció de nuevo con fuerza en la década de 1950. Por entonces, Carlos Seco editó, con un estudio preliminar, la obra del marqués de San Felipe y Pedro Voltes daba a la luz una biografía sobre el archiduque y diversos trabajos sobre la Guerra de Sucesión en Cataluña. ${ }^{26}$, inicio de lo que sería

Alacant en 1985. Historia de la ciudad de Denia, 2 vols., Dénia, 1874-76. Hay una edición facsímil publicada en Valencia en 1992.

25. MÑana, La Guerra de Sucesión, op. cit.

26. Wutes Bou, Pedro, El Archiduque Carlos de Austria, Rey de los catalanes, Barcelona, 1953. 
una prolífica aportación a la historiografía catalana y española. Por lo que se refiere al País Valenciano, el primero de los estudios fue publicado en 1956 por Vicente Gascón Pelegrí2 ${ }^{27}$, quien, desde una perspectiva militar, retomaba el hilo de Minyana para centrarse en los aspectos bélicos del conflicto, ampliando los datos conocidos, pero sin aportar nuevos enfoques. Por el contrario, los primeros pasos para abrir nuevos caminos y perspectivas fueron dados por Pedro Voltes ${ }^{28}$, quien gracias a sus trabajos sobre el archiduque Carlos y Cataluña, había conseguido reunir un conjunto de documentos inéditos y de gran interés relacionados directa o indirectamente con el Reino de Valencia, lo que le permitió reflejar, aunque con trazos discontinuos, algunos de los momentos cruciales del periodo y abrir nuevos interrogantes sobre los orígenes de la sublevación o los problemas del gobierno del Archiduque. También Henry Kamen dio a la prensa en esos años un libro sobre la Guerra de Sucesión en España ${ }^{29}$, en el que dedica sendos capítulos a Valencia. Aunque para llevar a cabo su propósito tuvo que utilizar un extenso bagaje documental, el carácter general de la obra no permitió a su autor profundizar en todos los ámbitos, si bien por primera vez un historiador trataba de descifrar las claves de la rebeldía de los valencianos, enfatizando el carácter popular ya señalado por Minyana. De forma paralela, las aportaciones iniciales, aunque desiguales por su entidad, de Pedro Pérez Puchal y Mariano Peset abrieron las puertas de la historiografía valenciana al estudio de la abolición de los Fueros, un camino seguido después por otros muchos historiadores.

Por lo que se refiere a la moderna historiografía valenciana sobre la Guerra de Sucesión, el punto de arranque lo constituye la obra ya citada, Aproximació a la història del País Valencià. Para su autor, Joan Reglà, se trataba de un conflicto con una doble vertiente, internacional e interna, plano este último en el que se proyectaba fielmente el dualismo que, según sus hipótesis, había presidido el devenir del Reino de Valencia desde que fuera fundado por Jaime I, en este caso una lucha entre seguidores del archiduque Carlos, los campesinos, maulets, y los partidarios del Borbón, los señores, botiflers, tras la cual quedaba reflejada otra dualidad, la de la costa frente al interior. Proyectado hacia afuera de la Monarquía Hispánica, el conflicto sucesorio era para la Corona de Aragón y especialmente para Cataluña un enfrentamiento con su tradicional enemiga, Francia. Hacia el interior, el final de la guerra significó la victoria de la aristocracia terrateniente frente al campesinado y el triunfo del absolutismo y de la centralización frente al sistema federal de la Corona de Aragón, truncando así también la corriente neoforalista y el programa político por el que esta Corona trataba de hacer viable la pervivencia de su propio sistema de gobierno en el seno de la Monarquía Hispánica.

27. GASCón PELEgri, Vicente, La región valenciana en la Guerra de Sucesión, Valencia, 1956.

28. Voltes Bou, Pedro, La Guerra de Sucesión en Valencia, Valencia, 1964.

29. KAMen, Henry, The war of Succession in Spain, 1700-1715, London, 1969. Hay edición española bajo el título La Guerra de Sucesión en España, 1700-1715, Madrid, 1974. 
Tomando como punto de partida estas hipótesis, se presentó en el $I$ Congreso de Historia del País Valenciano, celebrado en 1971, una comunicación bajo el título La Guerra de Successió: una revolució camperola ${ }^{30}$. En ella, después de situar el conflicto en su perspectiva internacional y en el marco de una confrontación, en el seno de la Monarquía Hispánica, entre un proyecto político de signo absolutista y centralizador y otro de carácter pactista, el citado trabajo entraba de lleno en lo que constituía uno de los aspectos más significativos y peculiares del conflicto sucesorio en el País Valenciano, las reivindicaciones antiseñoriales. Aún hoy en día, cuando el estudio de las rebeliones en los distintos reinos de la Corona ha avanzado considerablemente, es indiscutible que las reivindicaciones campesinas adquirieron en este caso una relevancia y una magnitud que no alcanzaron en otros territorios, aunque no se les sea ajena del todo la problemática antiseñorial. Esta relevancia estaba motivada por dos factores que entonces aparecían formulados, por un lado, el marcado clima de descontento existente en el señorío valenciano, resultado de las duras cartas de población firmadas entre señores y vasallos a partir de la expulsión de los moriscos, y de otro, las promesas de abolición del régimen señorial y de disminución de la fiscalidad hechas por los emisarios del archiduque Carlos y especialmente por don Juan Bautista Basset y don Francisco García de Ávila. Dicho en otras palabras, la estrategia de los dirigentes aliados para consolidar el apoyo de las clases populares a la causa carolina tuvo muy en cuenta la realidad socioeconómica y los antecedentes históricos del País Valenciano, independientemente de que valencianos, aragoneses y catalanes compartieran el objetivo principal, la defensa de la Casa de Austria frente a la Casa de Borbón. Conviene al mismo tiempo recordar y destacar al respecto el interés despertado entonces por el estudio de la revuelta campesina de 1693, conocida con el nombre de Segunda Germanía ${ }^{3 !}$, antecedente inmediato de las reivindicaciones hechas al gobierno del archiduque, y al mismo tiempo por el régimen señorial, un campo en el que la historiografía valenciana fue realmente pionera con trabajos importantes sobre distintos señoríos que aportaron nuevas perspectivas al estudio del feudalismo.

Sin embargo, y aunque el conflicto sucesorio se abordaba desde la perspectiva antiseñorial, no se reducía ni limitaba a esta problemática. Ya de entrada, el movimiento austracista en el País Valenciano quedaba entonces perfilado por una pluralidad sociológica que abarcaba otros colectivos, como la pequeña y mediana nobleza, precisamente aquélla más vinculada a las instituciones forales, el bajo clero, las clases

30. PÉrez APAricio, Carme, «La Guerra de Successió: una revolució camperola», I Congreso de Historia del País Valenciano, 4 vols., Valencia, 1973-1980, III, 1976, págs. 511-524. Esta comunicación avanzaba los primeros resultados de un trabajo de tesis doctoral sobre la Guerra de Sucesión en el País Valenciano, llevado a cabo bajo la dirección de Joan Reglà.

31. Hay que destacar entre los estudios llevados a cabo los de GARCía MarTínEZ, Sebastián, Els fonaments del País Valencià Modern, Valencia, 1968. Del mismo autor, «Francesc Garcia y la Segunda Germanía en la Marina Alta, Ier Congrés d'Història de la Marina Alta, Alicante, 1986, págs. 13-104 y Valencia bajo Carlos II. Bandolerismo, reivindicaciones agrarias y servicios a la Monarquia, Valencia, 1991. También Kamen, Henry, «Nueva luz sobre la Segunda Germanía de Valencia de 1693», Homenaje al Dr: D. Juan Reglà Campistol, 2 vols. Valencia, 1975, I, págs. 647-659. 
urbanas y una parte significativa del mundo rural, especialmente el sometido a la jurisdicción señorial. En definitiva, un espectro sociológico que, a grandes rasgos, coincidía con el de los otros territorios de la Corona de Aragón, como los estudios posteriores pusieron de relieve. Los objetivos también aparecían entonces formulados, la defensa del pactismo, que en aquel momento aparecía reflejado en la corriente neoforalista, la defensa de los intereses económicos de los gremios y comerciantes y la supresión de las prestaciones señoriales, en consonancia con las promesas de abolición formuladas por Basset. Al mismo tiempo se apuntaban otras razones importantes del descontento social, como las derivadas de la interrupción del comercio a causa de la guerra, con el consiguiente descalabro de una economía agrícola y muy vinculada a los mercados de Inglaterra y Holanda, ampliando al mismo tiempo el marco cronológico tradicional, que hasta entonces se abría en agosto de 1705 con el desembarco aliado, con el fin de buscar los antecedentes.

De igual manera el periodo de gobierno del archiduque Carlos adquiría por primera vez perfiles propios, desconocidos e ignorados por la historiografía tradicional, y que establecían claramente los dos componentes del austracismo valenciano, una corriente populista y radical encabezada por Basset y otra de carácter más moderado, impulsada por el propio archiduque y personificada en el virrey conde de Cardona, que intentaba sumar voluntades en la defensa de la causa. La primera pretendía hacer efectivas de inmediato las promesas de rebaja fiscal y supresión de los derechos señoriales, una medida estrictamente política que no podía encontrar soporte jurídico en los Fueros valencianos, tal y como ya había dictaminado la Real Audiencia apenas unos años antes en respuesta a las reclamaciones presentadas en 1693 y que pretendían sustentarse en unos supuestos privilegios que no fueron tomados entonces en consideración por el tribunal. La segunda corriente, aunque de signo integrador, trataba por encima de todo de mantener la hegemonía de las clases dominantes y el respeto por el ordenamiento jurídico, factor éste último que desembocó en el reconocimiento, por parte de la Real Audiencia, del derecho de los señores o de la Iglesia a la percepción de las rentas señoriales y el diezmo, algo que, por afectar a derechos de terceros, no estaba en manos del archiduque el suprimir sin violar los Fueros.

Con todo, la política llevada a cabo por el gobierno austracista, que entonces se vislumbraba por primera vez, no se limitaba al ámbito señorial y así la citada comunicación recogía también aunque de manera más general la política de represalias contra los franceses y la nobleza borbónica, la creación de las Juntas de Secuestro, la frustrada convocatoria de Cortes, las dificultades financieras del gobierno del archiduque, el aumento de la fiscalidad o la concesión de mercedes, honores y privilegios, cuestiones todas ellas que cambiaban radical y sustancialmente el panorama historiográfico conocido hasta entonces. A todo ello se añadía el estudio de las inmediatas consecuencias de la victoria borbónica de Almansa. De entrada una dura y sistemática represión, la abolición de los Fueros y la introducción de un nuevo sistema de gobierno, de una nueva fiscalidad, las protestas y el descontento generados por un castigo desproporcionado e indiscriminado y sobre todo la reacción de la clase política borbóniça, solicitando la revocación del Decreto, y las de los seguidores más radicales del austracismo, prota- 
gonizando un movimiento de guerrillas cuyo alcance agravaría considerablemente la inestabilidad social, política y militar que caracteriza los primeros años de la aplicación de la Nueva Planta.

Sobre estas bases, los estudios posteriores sobre la Guerra de Sucesión en el País Valenciano han tratado de profundizar en algunas de las líneas aquí señaladas y abrir otras nuevas. El interés de todos ellos es haber sacado a la luz documentos en su mayor parte inéditos, que son los que han permitido el avance experimentado por el tema en las últimas décadas. Una de las primeras líneas de estudio fue la que tomaba en consideración los estrechos vínculos existentes entre los intereses económicos valencianos y los de los países del Norte de Europa, especialmente Inglaterra y Holanda ${ }^{32}$. De esta manera, la ralentización de los intercambios primero y la posterior prohibición de comercio con los aliados a causa de la guerra, con el consiguiente predominio de los intereses comerciales galos, quebraron las bases de la economía valenciana y se configuraron como otro de los factores dignos de ser tenidos en cuenta para explicar la favorable acogida dispensada a las embarcaciones aliadas que se acercaron a Altea en $1703,1704 \mathrm{y}$, sobre todo, en $1705 \mathrm{y}$ al mismo tiempo el aumento de la francofobia, ya destacada por el historiador Minyana. Esta línea de investigación sería ampliada poco después con el estudio de los proyectos económicos que el gobierno inglés pretendía hacer realidad en suelo valenciano ${ }^{33}$, poniendo de relieve que su participación en la Gran Alianza no sólo buscaba el mantenimiento del equilibrio europeo sino también conseguir importantes ventajas en el vasto mercado colonial español y al mismo tiempo afianzar su presencia en el Mediterráneo occidental. En este sentido ingleses y valencianos perseguían, junto con Cataluña, los mismos objetivos, poder penetrar en el mercado colonial e impulsar las corrientes de comercio entre los puertos valencianos, especialmente el de Alacant, y los del norte europeo y más en concreto Londres. No hay que olvidar, por otro lado, que en esta misma línea incidirían algunas de las rebajas impositivas ofrecidas por el gobierno austracista, además de las de carácter antiseñorial, cuya finalidad respondía también a un deseo de mejorar la competitividad de los productos valencianos y aumentar el comercio.

Desde la perspectiva social, el primer grupo que mereció un estudio específico fue el clero, en consonancia con el protagonismo indiscutible desarrollado en las campañas a favor del archiduque desde la llegada al trono de Felipe $\mathrm{V}^{34}$. Tras él, la

32. Pérez Aparicio, Carmen, «El comercio y su repercusión en la Guerra de Sucesión en Valencia», Homenaje al Dr. D. Juan Reglà Campistol, 2 vols., Valencia, 1975, II, págs. 35-42.

33. Pérez APARICIO, Carmen, «El expansionismo comercial británico en el País Valenciano: El proyecto de creación de Puerto Franco en Alacant en 1706», Revista de Historia Moderna. Anales de la Universidad de Alicante, 11, 1992, págs. 251-264. Este trabajo había sido presentado en el Congreso Ciudad y Mar en la Edad Moderna, celebrado en Murcia y Cartagena en 1984.

34. Pérez APARICIO, $M^{a}$ Carmen, «El clero valenciano a principios del siglo XVIII: la cuestión sucesoria», V.V. A.A., Estudios de Historia de Valencia, Valencia, 1978, págs. 247-278. 
nobleza austracista, tanto a título colectivo ${ }^{35}$ como individual ${ }^{36}$, poniéndose de relieve que, independientemente de su respuesta a las promesas de supresión de los derechos señoriales, su actitud ante el conflicto sucesorio será el resultado no sólo de un apoyo a la Casa de Austria frente a la de Borbón, sino de un complejo entramado de circunstancias familiares y redes clientelares. El estudio de otros colectivos ha enriquecido en los últimos años el panorama sociológico que se deriva de la Guerra de Sucesión, tanto por lo que se refiere a los de carácter filoborbónico, tal es el caso de los notarios, como filiaustracistas, como lo eran la mayor parte de los gremios de la capital ${ }^{37}$. Finalmente, y por lo que se refiere al campesinado, las aportaciones a este campo se han centrado fundamentalmente en el estudio del clima de malestar existente en vísperas de la sublevación ${ }^{38}$ con el estudio de los procesos relacionados con el señorío que se sustanciaron en la Real Audiencia entre 1693 y 1705 y cuya resultado permitió introducir un elemento nuevo para explicar las reivindicaciones formuladas en una y otra fecha, como era la difusión de una mentalidad contraria al régimen señorial sustentada en el derecho natural. No se puede olvidar tampoco el relevante peso historiográfico que ha alcanzado la figura de Basset ${ }^{39}$, un personaje vituperado en su época por los sectores más conservadores de la sociedad y por la historiografia borbónica, y al mismo tiempo convertido en ídolo de las clases populares, faceta esta última que es la que los recientes estudios han tratado de realzar hasta presentarlo hoy, gracias a nuevas aportaciones documentales, como un héroe por su trayectoria militar, su defensa de los intereses populares y su valerosa y entregada participación en la defensa de Barcelona.

De otra parte, la trascendencia de algunos momentos o hechos relacionados con la sucesión de Carlos II o con episodios desencadenados con motivo de la guerra han atraído también la atención de algunos historiadores. Es el caso la respuesta institucional a las disposiciones testamentarias del último Austria $^{40}$, la reacción causada por el

35. Girquillo Pérez, Juan A., «La nobleza austracista en la guerra de Sucesión. Algunas hipótesis sobre su participación», Estudis. Revista de Historia Moderna, 17, Valencia, 1991, págs. 115-147.

36. rérez Aparicio, Carmen, «Una vida al servicio de la Casa de Austria. Don José Folc de Cardona y Erill, príncipe de Cardona», Estudis. Revista de Historia Moderna, 17, Valencia, 199l, págs. 421-448. FELIPO, Amparo, «Aproximación al estudio de un austriacista valenciano. El conde de Villafranqueza», Disidencias y exilios en la España Moderna, Actas de la IV Reunión cientifica de la Asociación Española de Historia Moderna, Antonio Mestre Sanchis y Enrique Giménez López, eds., Alicante, 1997, págs. 515-542.

37. Graullera Sanz, Vicente, Los notarios de Valencia y la Guerra de Sucesión, Valencia, 1978.

38. Pérez Aparicio, Carmen, «Reivindicaciones antiseñoriales en el País Valenciano. De la Segunda Germanía a la Guerra de Sucesión», Estudis. Revista de Historia Moderna, 17, Valencia, 1998, págs. 246-279

39. Gervera Torrejón, José Luis, Basset, mite i realitat de l'heroi valencià, Valencia, 2003.

40. PÉrez ApAricio, Carmen, «Austrias y borbones. Las repercusiones del cambio dinástico en el País Valenciano», Saitabi. Revista de la Facultad de Geografia i Historia, XLIII, Valencia, 1993, págs. 231242. 
desembarco aliado en Altea en $1704^{41}$, los primeros años del gobierno filipista ${ }^{42}$ o la destrucción de Vila-real por las tropas borbónicas en 1706. Al mismo tiempo y como consecuencia de la complejidad del tema y de las dificultades para abarcar de entrada toda la geografía valenciana han aparecido numerosos trabajos que abordan el estudio de la Guerra de Sucesión desde una perspectiva local, ya sea mediante estudios específicos, ya sea en el marco de obras cronológicamente más amplias ${ }^{43}$. Entre los de carácter monográfico destacan aquéllos destinados a las principales poblaciones. Uno de los primeros se centró en la villa de $\mathrm{Alcoi}^{44}$, un estudio que arrancaba de 1700 para seguir paso a paso los problemas derivados de la defensa de la Monarquía y las repercusiones de la sublevación a partir de las fuentes documentales de carácter municipal. A él le siguieron el de la ciudad de Valencia ${ }^{45}$, auténtica caja de resonancia de todos los problemas que por entonces sacudieron todo el Reino. En este caso, nuevamente se enmarcaba el conflicto en una lucha internacional por mantener el equilibrio europeo, en la defensa del sistema pactista por parte de la Corona de Aragón, resultado de un arraigado sentimiento foral, al que se unía la francofobia generada por la política imperialista gala y el conflicto de intereses económicos y junto a ello, la tradicional inquietud el campo valenciano. A partir de estas bases, el estudio se centraba en los problemas del gobierno austracista y las primeras consecuencias de la abolición de los Fueros.

Otra de las ciudades valencianas que tuvo pronto un estudio monográfico fue la de Alacant ${ }^{46}$. En este caso, el planteamiento inicial tenía también como puntos básicos de referencia el conflicto y los intereses internacionales, la estrategia aliada para asentar sus bases en la propia Monarquía y la evolución de los acontecimientos hasta la firma de las Paces. Por otro lado y antes de entrar de lleno en el estudio de las fuentes docu-

41. GMĹNEZ LÓPEZ, Enrique, «El desembarco aliado en Altea en 1704 y el virrey marqués de Villagarcía», Homenatge al Dr: Sebastià Garcia Martínez, II vols. Valencia, 1988, II, págs. 269-284.

42. Villamarin GómeZ, Sergio, «La política del marqués de Villagarcía durante el primer reinado de Felipe V》, Saitabi. Revista de la Facultad de Geografia i Historia, 51-52, Valencia, 2001-2002, págs. 379-400. López CAMPS, Joaquim E., «La invasió austriacista del Regne de València» (1701-1705)», Afers. Fulls de Recerca i Pensament, 52, Catarroja, 2005, págs. 521-540.

43. VLAR, Juan Bautista, Orihuela, una ciudad valenciana en la España Moderna. Historia de La Cindad y Obispado de Orihuela, Murcia, 1981, IV, págs. 677-688. Mercedes DIAZ-PLAZA, «La Guerra de Sucesión en Segorben, Boletin del Centro de estudios del Alto Palancia, Año II, n¹1, 1986, págs. 71-86. Bernabeu i SANCHIS, Alfred, Ontinyent,vila reial. De les Germanies a la Nova Planta, 1992. GiméNez López, Enrique, «La Guerra de Sucesión en la comarca de la Marina», III Congrés d'estudis de la Marina Alta, Alicante, 1992, págs. 277-281. JOvER, Francesc, «La Guerra de Successió a Cocentaina», Alberri, Quaderns d'Investigació del Centre d'Estudis Contestans, 11, Cocentaina, 1998, págs. 67-157, Vallés Borràs, Vicent J., L'Alcridia, 750 anys. De la Carta de Poblament a l'ocàs de l'antic règim (1252-1800), L’Alcúdia, 2002, págs. 353-377.

44. SANChIS LLORENS, Rogelio, Alcoy y la Guerra de Sucesión, Alicante, 1969.

45. PÉrez APARICIO, Carme, De l'alçament maulet al triomf hotifler, Valencia, 1981. Este trabajo fuc el resultado de la reelaboración de una tesis de licenciatura que bajo el título de «La Guerra de Sucesión en la ciudad de Valencia» fue presentada en 1968.

46. Pradells NADAL, Jesús, Del foralismo al centralismo. Alicante 1700-1725, Alicante, 1984. 
mentales, su autor realizaba un completo análisis historiográfico en el que se ponía de manifiesto la amplitud y complejidad de las perspectivas desde las que se había analizado el tema desde el siglo XVIII hasta la actualidad. En cuanto a los objetivos principales del libro, el primero era el de reconstruir los hechos vividos en las comarcas del sur valenciano, especialmente en Alacant y Oriola, tomando como punto de partida las Crónicas pero incorporando las fuentes documentales de carácter local. La segunda parte estaba destinada al estudio de las confiscaciones decretadas por Felipe $\mathrm{V}$ tras la capitulación de Valencia. En este sentido, hay que señalar no sólo que el radio de análisis sobrepasaba el propósito inicial del libro, sino que abría un nuevo camino sobre una de las facetas derivadas del triunfo filipista y al mismo tiempo permitía acercarse al colectivo más destacado de los seguidores del archiduque, un camino que otros historiadores recorrerían más tarde para estudiar las confiscaciones llevadas a cabo por el gobierno austracista ${ }^{47}$.

El problema del exilio es otro de los que se ha incorporado con pleno derecho en la reciente historiografia, especialmente el austracista, si bien pronto se podrá completar con el que sufrieron los partidarios de Felipe $\mathrm{V}^{48}$. Aunque el exilio de los más directos seguidores del archiduque se puede rastrear en las obras de carácter general dedicadas al tema ${ }^{49}$, éste es un aspecto que no ha sido aún estudiado en toda su dimensión ${ }^{50}$. Existen, no obstante, aportaciones sobre algunos de los más destacados dirigentes ${ }^{51} \mathrm{o}$ sobre otros menos conocidos integrantes de las filas austracistas ${ }^{52}$.

47. El tema sería ya apuntado por Graullera SANZ, Los notarios..., op. cit., págs. 64-69, y desarrollado posteriormente por PÉREZ. APARICIO, Carmen, «La política de represalias y confiscaciones del archiduque Carlos de Austria», Estudis. Revista de Historia Moderna, 17, Valencia, 1991, págs. 149-196. Felipo ORTS, Amparo, «Las repercusiones de la política de confiscaciones de Felipe V sobre Don Juan Basilio de Castellví, conde de Cervelló y marqués de Villatorcas», Estudis, Revista de Historia Moderna, 31 , 2005 , págs. $253-268$.

48. El prof. Enrique Giménez López tiene actualmente entre sus manos este tema, como puede leerse en este mismo número de la Revista.

49. SIIFFONI, Giovanni, «Un documento inédito sobre los exiliados españoles en los dominios austríacos después de la Guerra de Sucesión〉, Estudis. Revista de Historia Moderna, 17, Valencia, 1991, págs. 755. LEÓN SANZ, Virginia, Entre Austrias y Borbones. El Archiduque Carlos y la monarquía de España (1700-1714), Madrid, 1993. De la misma autora «La oposición a los borbones españoles, los austriacistas en el exilio», en Disidencias y exilios en la España Moderna, A. Mestre Sanchis y E. Giménez. López, eds., Alicante, 1997, págs. 469-499. AlCOBERro, Agustí, L'exili austriacista (1713-1747), 2 vols. Barcelona, 2002.

50. José Luis Cervera Torrejón ha llevado a cabo en los últimos años una cuidada tarea de recopilación de datos sobre exiliados valencianos y es de desear que dé pronto a la imprenta este interesante trabajo.

51. Pérez Apariclo, Carmen y Felipo OrTS, Amparo, «Un drama personal i col-lectiu. L'exili austriacista valencià», Pedralbes. Revista d'Historia Moderna. Catalunya i Europa a l'Edat Moderna, 18, Barcelona, 1998, págs. 329-343. Perez APARICIO, «Una vida al servicio...», op. cit.

52. LOPEZ CAMPS, Joaquim Enric, «Maulets amb noms i cognoms. Els exiliats valencians a Barcelona», Enfrontaments civils: postguerres i reconstruccions. Segon Congrés Recerques, LIeida, 2002, I, págs. 176-192. 
Aunque sin ánimo de recoger de manera exhaustiva todas las aportaciones al tema y con el riesgo consiguiente e inevitable de algún olvido involuntario, la Guerra de Sucesión en el País Valenciano presenta, pues, un panorama que, si no es plenamente satisfactorio, es cuando menos esperanzador. Un balance reciente del estado de nuestros conocimientos sobre el tema fue el que se presentó en enero de 2001 con motivo del Congreso celebrado entonces en Zaragoza para conmemorar la llegada al trono español de la dinastía francesa ${ }^{53}$. Tras un breve repaso historiográfico, se recogían los aspectos más relevantes que ya se han ido señalando, pero también se introducían nuevos planteamientos y nuevos interrogantes. El primero de ellos rastrear el clima de opinión existente en la sociedad valenciana a propósito de la sucesión, tarea nada fácil por el hermetismo de las fuentes pero algunas de cuyas manifestaciones pudieron ser detectadas en los círculos literarios y científicos de la capital. Después, y dejando a un lado la ya conocida aceptación incondicional de las instituciones valencianas de las disposiciones testamentarias de Carlos II, descubrir las actitudes contrarias y especialmente las razones que se esgrimieron entonces para rechazar el cambio dinástico. En este sentido se señalaban las de carácter jurídico y político, es decir, la legitimidad o no de Carlos Il para designar heredero y la idoneidad del elegido, como los primeros factores que abrieron paso a la disidencia entre los valencianos y junto a ellos la defensa de un sistema político pactista, en el que se atribuía a las Cortes, como representantes del Reino, la capacidad de elegir sucesor, frente a los argumentos difundidos en sentido contrario por la propaganda borbónica de considerar la voluntad de Carlos II y también la pacífica posesión de la Monarquía por parte de Felipe $\mathrm{V}$ como expresión de la voluntad divina. En definitiva, la defensa de un sistema constitucional, con las Cortes como máxima institución representativa, frente a una concepción absolutista del poder. A esta primera causa se añadiría la francofobia, como resultado de la política imperialista de Luis XIV que había tenido en la Corona de Aragón el escenario principal de sus campañas militares en la Monarquía. En definitiva, el germen de la disidencia política arrancaba desde el mismo momento de la entronización de Felipe $\mathrm{V}$ y era compartido por todos los Reinos de la Corona.

La política llevada acabo por el primer gobierno borbónico fue añadiendo nuevos factores al descontento inicial de los valencianos. En primer lugar la falta del preceptivo juramento de los Fueros así como la no celebración de Cortes, y eso a pesar de la insistencia de las peticiones y de los trabajos preparatorios que se pusieron en marcha $^{54}$. Después la declaración de guerra internacional, con la consiguiente interrupción del comercio con los países del Norte, especialmente Inglaterra y Holanda, lo que acarreó consecuencias muy negativas para la economía valenciana por su estrecha

53. Plérez Apariclo, Carmen, «Cambio dinástico y disidencia política en el País Valenciano», Felipe Vy su tiempo. Congreso Internacional, Eliseo Serrano, editor, 2 vols., Zaragoza, 2004, págs. 119-149.

54. Este tema habia sido ya abordado anteriormente. Pérez APARICIO, Carmen, «El proceso de consolidación de la Monarquía autoritaria y la reacción foral. La Junta de Contrafurs», Mayans y la Ilustración. Simposio internacional en el Bicentenario de la muerte de Gregorio Mayans, Oliva, 1982, págs. 131151. 
vinculación con los citados países. De otro lado, los grandes beneficios obtenidos por los comerciantes franceses y los abusos practicados por las embarcaciones galas, con el pretexto de controlar el comercio con países neutrales, contribuyeron a aumentar la francofobia y el rechazo hacia el Borbón. Las manifestaciones de disidencia aparecieron incluso antes de la llegada de Felipe $\mathrm{V}$ a la Monarquía y las primeras que salieron a la luz estuvieron protagonizadas por el bajo clero y las clases populares, pero no parece arriesgado afirmar que todos los grupos sociales, en mayor o menor medida, participaron del apoyo a la Casa de Austria animados por las campañas clandestinas que llevaron a cabo diversos emisarios del Imperio y por la difusión de escritos favorables a su causa que circularon por toda la Monarquía.

Las reivindicaciones de carácter antiseñorial fueron un nuevo elemento a añadir a los anteriores causas de descontento. Su aparición se detecta a partir de 1703, coincidiendo con el paso de la armada aliada por las costas valencianas y su detención en Altea para cargar agua. Es con motivo de una nueva incursión aliada en 1704 cuando se produce el desembarco del que será después líder popular, don Juan Bautista Basset, y cuando él y otros emisarios del Imperio llevarán a cabo intensas campañas de captación, bajo la promesa de supresión de las prestaciones señoriales. En este sentido se afirmaba que estas promesas, con las que se pretendía captar para la causa aliada a un amplio sector del campesinado de señorío, lejos de constituir la causa de la rebelión, se sumaron a los factores de carácter dinástico, político y económico que estaban en la base del austracismo valenciano. A todo ello vino a sumarse la falta de respuesta del gobierno borbónico a las peticiones formuladas por las instituciones valencianas de tropas regladas para la defensa del Reino, lo que provocó un enfriamiento en la relaciones entre el rey y el Reino y hasta manifestaciones del descontento existente, lo que unido a la formidable presencia de los aliados en las costas propició el triunfo de la rebelión.

Con la capitulación de Dénia y sobre todo con la de Valencia el gobierno austracista pudo llevar a la práctica sus aspiraciones. En la primera etapa, bajo el gobierno de Basset, fueron las clases populares las que trataron de imponer su programa de reducción de la fiscalidad y de persecución y confiscación de bienes de los franceses y de la nobleza. Después, la presencia en el virreinato del conde de Cardona permitió reconducir la situación y abordar los grandes retos que tenía planteados su gobierno. De un lado el propio Basset y la supresión de los derechos señoriales, una verdadera prueba de fuego para el nuevo gobierno, que pudo ser superada, a pesar de las protestas populares por la detención del general y de las resoluciones de la Real Audiencia a favor de los perceptores de los derechos y del diezmo, por la tolerancia practicada de facto respecto a los vasallos de los señoríos confiscados. Por otro lado y por lo que se refiere a las relaciones entre el rey y el Reino, se resaltaba entonces la dificultad de sacar conclusiones respecto al proyecto político austracista, como consecuencia del breve periodo de gobierno de Carlos III y sobre todo de la desaparición de las fuentes documentales donde hubieran tenido que reflejarse estas cuestiones. Lo cierto es que Carlos III hizo gala en todo momento de un escrupuloso respeto por los Fueros que juró en la Seo, a diferencia del propio Felipe V e incluso de Carlos II, pero no convocó las Cortes, 
algo que realmente hubiera permitido conocer el alcance de las reivindicaciones de los valencianos. La afirmación que hizo Castellví en sus Memorias de que los Reinos de la Corona pretendían retrotraer las relaciones con la Monarquía al estado en que se hallaban durante el reinado de Fernando el Católico permitía deducir que, más que una simple restauración de la Casa de Austria, el objetivo final era el de mantener el sistema pactista pero erradicando las malas prácticas de los últimos Habsburgo. Mayor concreción alcanzaron los proyectos económicos basados en una reducción de la físcalidad sobre los productos de consumo, una mayor libertad de comercio, la apertura de nuevos mercados y la consolidación de los ya existentes, proyectos éstos dos últimos que se plasmaron en dos propuestas muy ambiciosas, la de establecer la libertad de comercio con la Corona de Castilla y todos los territorios a ella incorporados, incluidas la Indias, y la creación de un puerto franco en Alacant para los productos ingleses. Se trataba, en definitiva, de proyectos de modernización económica, profundo cambio social y revitalización del sistema político que no pudieron ver entonces la luz.

El panorama que presentaba el tema en el 2001 se completaba con una perspectiva sociológica del austracismo, que, si bien no variaba, en cuanto a la composición de sus fuerzas, respecto de lo que se ha venido afirmando, sí que abordaba la dificultad de explicar las distintas posiciones adoptadas por un mismo colectivo. Quizá sea ésta una de las cuestiones abiertas, capaz de suscitar opiniones diversas, pero necesitada también de estudios más profundos. En este sentido, conviene tener en cuenta que, por lo que se refiere a la nobleza titulada, parece claro que su postura proborbónica se debió al hecho de que algunos titulares de grandes señoríos, Gandia, Medinaceli, Santiesteban, residian en la corte y estaban al servicio del Borbón, de quien habían recibido mercedes y honores. En otros casos, especialmente de todos aquellos que solicitaron pasaporte a Basset para salir de la capital, la razón de su marcha bien podía estar relacionada con los sucesos vividos en la capital y que habían desembocado en asaltos a las casas de franceses y de la nobleza y confiscación de sus bienes, así como con las promesas de supresión de las prestaciones señoriales. Por supuesto habría que contar con que entre los nobles existía un sector que se venía caracterizando por una estrecha colaboración con el virrey, algunos de cuyos nombres --escasos, por cierto-son conocidos por figurar en los informes suscritos por el marqués de Villagarcía. En sentido contrario, y aunque las relaciones del virrey con la nobleza fueron fluidas, no faltaron las desavenencias a causa del comportamiento de algunos de sus miembros por ser contrarios a aceptar algunas de las directrices llegadas desde la corte en los primeros momentos después de la muerte de Carlos II o en relación con la declaración de Felipe V de alterar las líneas sucesorias establecidas por el testamento del último Austria. Sin embargo, las dificultades para perfilar la divisoria entre quienes apoyarían al archiduque con la esperanza de una revitalización del sistema pactista, respecto de quienes acataban al Borbón son también el resultado de un general desconocimiento de la clase política en la Edad Moderna, lo que constituye una asignatura todavía pendiente de la historiogra- 
fía valenciana ${ }^{55}$. A mayor abundamiento, la falta de convocatorias de Cortes durante el reinado de Carlos II y sobre todo el hecho de que ni Felipe $V$ ni al archiduque convocaran las Cortes valencianas, a diferencia de Catalunya, ofrece una mayor dificultad al respecto, lo que se une al hermetismo que caracteriza las fuentes, a la desaparición de los registros correspondientes al periodo de gobierno austracista y también a la brevedad de este periodo, a diferencia del caso catalán.

Relacionados con todos estos factores está también el de los objetivos políticos de los austracistas valencianos. Dejando a un lado el común denominador de todos los Reinos de la Corona de Aragón en la defensa del sistema pactista, como fue ya recogido por los historiadores borbónicos del siglo XVIII y situado en el punto de partida de los estudios recientes, resulta de momento mera especulación cualquier otra hipótesis que sobrepase el deseo manifestado explícitamente por los valencianos de que el rey jurase los Fueros y convocase Cortes y de que éstas consiguiesen la aprobación del mantenimiento de la Junta de Contrafueros y la mejora de los mecanismos existentes para evitarlos y repararlos, tal y como quedó recogido en los Apuntaments redactados por la Junta de Electos de Estamentos entre 1701 y 1702. Es decir, por lo que sabemos, no hay un proyecto político alternativo al pactismo sino una reforma del sistema conducente a corregir los abusos del autoritarismo monárquico. Hoy por hoy, la falta de las actas de las Juntas del Estamento Militar y de las de Electos de Estamentos no permite adelantar más en esta dirección. Queda, eso sí, una posibilidad que ya fue apuntada en la ponencia presentada en Zaragoza en el 2001 y que permanece abierta como es la de estudiar la publicística sobre el tema, una perspectiva iniciada en $1960^{56}$ y recuperada recientemente ${ }^{57}$, pero que debe ser abordada con carácter general, ya que el anonimato de estos escritos y su amplísima difusión territorial no permite diferenciar de manera precisa entre la publicística valenciana, castellana, catalana o de cualquier otra procedencia. En cualquier caso, no parece que el breve periodo de gobierno austracista, el más breve todavía de estancia del archiduque en tierras valencianas y la falta de contenciosos importantes entre Carlos III y el Reino, suscitase debates de mayor alcance que la propuesta frustrada de celebrar Cortes o la discusión del proyecto de Unión de Armas de la Corona de Aragón. Unas circunstancias, en definitiva, muy diferentes de las de Cataluña, que tuvo que soportar durante más tiempo la presencia de los aliados y que se vio abocada, especialmente tras la marcha del emperador, a buscar una nueva vía para salvar la orfandad austríaca y la intransigencia absolutista e inmisericorde de Felipe V.

En cuanto al resto de los grupos sociales, el bajo clero jugó, como se sabe, un papel protagonista desde la llegada al trono del Borbón. Las causas apuntadas más

55. El historiador James Casey ha abordado esta cuestión en algunos de sus trabajos. CASEY, James, El Regne de València en el segle XVII, Barcelona, 1981. Existe traducción castellana.

56. PÉrez PiCAzo, María Teresa, La publicistica española en la Guerra de Sucesión, 2 vols., Madrid, 1966.

57. AlABrús, Rosa María, Felip Vi l'opinió dels catalans, Lleida, 2001. García CÁrCEL, Ricardo, Felipe Virrey y los españoles, Barcelona, 2002. 
recientemente, como son el rechazo a la dinastía francesa por su trayectoria regalista, encajarían a la hora de explicar el comportamiento del clero de la Corona de Aragón y, de hecho, constituyeron uno de los factores principales, pero no sirven para explicar la actitud proborbónica del clero castellano. Es necesario, pues, formular otras hipótesis, no en clave religiosa sino política y social, compartidas con el resto del espectro. Lo mismo puede decirse del apoyo prestado por los sectores sociales relacionados con la manufactura y al comercio, cuya vinculación a la causa imperial se detecta ya en los inicios del nuevo gobierno borbónico, pero que se reafirmará después por la política económica desarrollada por el Borbón y los perjuicios causados por la interrupción del comercio con los países aliados.

Punto y aparte merece el campesinado valenciano, tanto por su importancia cuantitativa en el conjunto de la sociedad como por su cualificada participación en las filas austriacistas. De todos los colectivos sociales, es el más atención ha suscitado entre los historiadores desde el siglo XVIII hasta la actualidad. Tanto Minyana como los dietaristas de la época pusieron ya de relieve la estrecha conexión entre el movimiento conocido con el nombre de Segunda Germanía y las reivindicaciones formuladas durante el periodo austracista y no cabe duda de que las promesas hechas por Basset se sustentaban en un clima de descontento general en el señorío valenciano y tuvieron un amplio eco. A juzgar por el exhaustivo estudio de S. García Martínez, nada parece más alejado de la realidad que considerar la rebelión de 1693 como un acto de rebeldía primitiva. Por el contrario, se inicia como una respuesta colectiva y coordinada ante los abusos de algunos señores, pero también como una protesta contra el régimen señorial en su conjunto, planteada inicialmente por la vía pacífica de la administración de justicia y sustentada en unos privilegios -que no Fueros- supuestamente favorables a sus pretensiones.

Algunos historiadores ${ }^{58}$ han puesto de relieve la existencia de puntos en común con el movimiento de los barretinas catalanes de unos años antes, donde el malestar señorial se funde con el rechazo a los alojamientos, utilizados por los propios señores para el control y sometimiento de sus vasallos. Tampoco han faltado, con igual razón, quienes han subrayado las relaciones existentes entre el movimiento barretina y la Segunda Germanía, de un lado, y la Guerra de Sucesión, de otro, pero hay que tener en cuenta que las reivindicaciones antiseñoriales reaparecen en el marco de un conflicto que, en su origen, no es de naturaleza socioeconómica sino política y que, por tanto, no están en la causa del problema sino que, en el caso valenciano, aparecerán en el transcurso de los acontecimientos y de manera más concreta a partir de 1704, tras el desembarco aliado en Altea y la presencia de emisarios del imperio, Basset entre ellos, que ofrecen la supresión de las prestaciones señoriales a cambio del apoyo al archiduque. Se trata en este caso de un ofrecimiento politico, una medida de gracia, muy alejada, por tanto, de los planteamientos jurídicos que habían estado presentes en el origen de la Segunda Germanía. Entonces, las reclamaciones presentadas ante el

58. Aume DANTí I RIU, Aixecaments populars als Països Catalans, Barcelona, 1990. 
Consejo de Aragón y la Real Audiencia no habían prosperado por la insubsistencia de los fundamentos sobre los que se asentaba la demanda, unos privilegios medievales cuya aplicación al caso fue rechazada por la Real Audiencia.

Sin embargo, las esperanzas depositadas por los vasallos en las promesas de Basset se esfumaron de igual manera cuando la nobleza afectada reclamó ante la Real Audiencia el respeto a la legalidad y ésta, como lo había hecho unos años antes durante el reinado de Carlos II, volvió a reconocer que el régimen señorial se regulaba por los contratos establecidos entre señores y vasallos en las Cartas Pueblas y que obligaban por igual a ambas partes. Tampoco las instituciones representativas del Reino, los tres Estamentos, se pusieron del lado de los vasallos en esta reivindicación, ni en 1693 ni ahora, aunque sí lo hicieron en 1705 para denunciar ante Felipe V los abusos cometidos por los jefes militares borbónicos a propósito de los alojamientos, cuestión ésta que tanto en Cataluña como en Valencia sí que estaba regulada por los Fueros. En definitiva, ni podía haber una respuesta judicial favorable a la supresión de los derechos señoriales ni mucho menos política, porque, como el propio archiduque se vio obligado a declarar, estaba obligado a respetar los Fueros que había jurado. En consecuencia y puesto que la aparición de una corriente popular favorable al Austria se detecta ya antes incluso de la llegada del Borbón, parece evidente que las promesas de Basset, formuladas en vísperas de la sublevación, no estaban en el origen de la disidencia y que las razones fundamentales de la misma tenían sus raíces en el rechazo a la dinastía francesa, representante de una concepción política y de unos intereses económicos antagónicos con los de la Corona de Aragón. Todo ello sin menospreciar el amplio eco despertado por las promesas de Basset hasta el punto de añadir un renovado impulso a la causa imperial.

Con todo y aunque los intereses políticos, los proyectos económicos y las reivindicaciones sociales van encontrando cada vez más su propio perfil, aún quedan no pocas sombras en el panorama de la Guerra de Sucesión. Para empezar, sería necesario cubrir todo el ámbito geográfico del País Valenciano y completar los estudios de las grandes ciudades a partir de los archivos locales. De otro lado, son prácticamente desconocidos los planes llevados a cabo en la clandestinidad para preparar la rebelión y el verdadero alcance de los contactos mantenidos por los austracistas valencianos con el emperador y con otros territorios de la Monarquía. A su vez, la sociología y especialmente el estudio de los grupos dirigentes del austracismo podría arrojar alguna luz sobre el oscuro panorama que aún ofrece el mundo político valenciano. El exilio austracista es igualmente un campo poco explorado y muy necesario, por otro lado, para profundizar en el ámbito sociológico. En fin, a pesar del avance de los conocimientos sobre la Guerra de Sucesión en el País Valenciano siguen abiertos aún muchos interrogantes. 